IZA DP No. 6302

Envy, Guilt, and the Phillips Curve

Steffen Ahrens

Dennis J. Snower

January 2012

Forschungsinstitut zur Zukunft der Arbeit Institute for the Study of Labor 


\title{
Envy, Guilt, and the Phillips Curve
}

\author{
Steffen Ahrens \\ Kiel Institute for the World Economy \\ and Christian-Albrechts-University Kiel
}

Dennis J. Snower

Kiel Institute for the World Economy, Christian-Albrechts-University Kiel, CEPR and IZA

\author{
Discussion Paper No. 6302 \\ January 2012
}

\author{
IZA \\ P.O. Box 7240 \\ 53072 Bonn \\ Germany \\ Phone: +49-228-3894-0 \\ Fax: +49-228-3894-180 \\ E-mail: iza@iza.org
}

\begin{abstract}
Any opinions expressed here are those of the author(s) and not those of IZA. Research published in this series may include views on policy, but the institute itself takes no institutional policy positions.

The Institute for the Study of Labor (IZA) in Bonn is a local and virtual international research center and a place of communication between science, politics and business. IZA is an independent nonprofit organization supported by Deutsche Post Foundation. The center is associated with the University of Bonn and offers a stimulating research environment through its international network, workshops and conferences, data service, project support, research visits and doctoral program. IZA engages in (i) original and internationally competitive research in all fields of labor economics, (ii) development of policy concepts, and (iii) dissemination of research results and concepts to the interested public.
\end{abstract}

IZA Discussion Papers often represent preliminary work and are circulated to encourage discussion. Citation of such a paper should account for its provisional character. A revised version may be available directly from the author. 


\section{ABSTRACT}

\section{Envy, Guilt, and the Phillips Curve}

We incorporate inequity aversion into an otherwise standard New Keynesian dynamic equilibrium model with Calvo wage contracts and positive inflation. Workers with relatively low incomes experience envy, whereas those with relatively high incomes experience guilt. The former seek to raise their income, and latter seek to reduce it. The greater the inflation rate, the greater the degree of wage dispersion under Calvo wage contracts, and thus the greater the degree of envy and guilt experienced by the workers. Since the envy effect is stronger than the guilt effect, according to the available empirical evidence, a rise in the inflation rate leads workers to supply more labor over the contract period, generating a significant positive long-run relation between inflation and output (and employment), for low inflation rates. This Phillips curve relation, together with an inefficient zero-inflation steady state, provides a rationale for a positive long-run inflation rate. Given standard calibrations, optimal monetary policy is associated with a long-run inflation rate around 2 percent.

JEL Classification: D03, E20, E31, E50

Keywords: inflation, long-run Phillips curve, fairness, inequity aversion

Corresponding author:

Steffen Ahrens

Kiel Institute for the World Economy

Hindenburgufer 66

24105 Kiel

Germany

E-mail: steffen.ahrens@ifw-kiel.de 


\section{Introduction}

Despite a well-known, growing body of empirical literature calling the classical dichotomy into question, it is still the conventional wisdom in contemporary macroeconomic theory that monetary policy is roughly neutral with respect to aggregate employment and output in the long run. Even though the standard New Keynesian model implies a non-neutrality due to time discounting and inefficiencies due to relative price instability, these long-run effects of monetary policy are quantitatively small for reasonable values of the interest rate and low inflation rates (Ascari (1998) and Graham and Snower (2004)). ${ }^{1}$ This paper, by contrast, offers a new rationale for long-run real effects of monetary policy, resting on envy and guilt. We find that for reasonably calibrated values of the relevant parameters, these long-run effects are substantial. This result has important implications for the conduct of mo- netary policy. Our calibration results suggest an optimal inflation rate in the neighborhood of 2 percent.

In particular, we incorporate fairness considerations to an otherwise standard dynamic stochastic general equilibrium (DSGE) model of New Keynesian type with Calvo nominal wage contracts and positive trend inflation. In this context, we show that the classical dichotomy (whereby nominal variables have no long-effect effect on real variables) breaks down in an empirically significant and theoretically novel way. Our rationale for the long-run non-neutrality of monetary policy does not rest on money illusion, departures from rational expectations, or permanent nominal rigidities. Instead, we assume that people are inequity-averse with respect to real incomes, following the seminal work from Fehr and Schmidt (1999) and Bolton and Ockenfels (2000). Accordingly, people with relatively low income experience envy, whereas those with relatively high income experience guilt. Both experiences generate disutility and, in according with the evidence, the influence of envy is stronger than that of guilt.

In the presence of Calvo nominal wage contracts, higher inflation implies greater wage dispersion and thus greater dispersion of incomes, generating more envy and guilt. Since people seek to mitigate envy and guilt, they adjust their employment accordingly. Those who experience envy seek to raise their income and do so by increasing their employment, where those who experience guilt reduce their employment. Since the envy effect is stronger than the guilt effect, higher inflation is associated with greater employment and output, thereby generating a long-run Phillips curve tradeoff.

In this context, we examine the welfare implications of our approach. We find that the optimal long-run inflation rate (maximizing steady-state, economy-wide household utility) is positive, in the neighborhood of 2 percent for the standard calibrations. This result is in stark contrast to earlier studies of DSGE models with trend inflation (e.g., King and Wolman (1996), Kahn et al. (2003), Yun (2005), and Schmitt-Grohé and Uribe (2007, 2010)), which find optimal monetary policy to either be given by price stability or even by following a de-

\footnotetext{
${ }^{1}$ This holds true for the standard assumption of exponential discounting. Graham and Snower (2008) show that hyperbolic discounting leads to a long-run trade-off of reasonable magnitude.
} 
flationary path. Our results are more in line with the aims of practical monetary policy, as practiced by central bankers.

The the paper is organized as follows. Section 2 reviews the relevant literature. Then section 3 describes our microfounded macro and calibrates it. Section 4 presents the numerical implicatons of the model for the long-run Phillips curve, discusses the underlying intuition, and investigates the sensitivity of the results with respect to key parameters. Section 5 examines optimal monetary policy in the presence of envy and guilt. Finally, section 6 concludes.

\section{Relation to the Literature}

Although evidence regarding verticality of the long-run Phillips curve had been mixed over the past century, recent years have witnessed a rapidly growing literature calling the classical dichotomy into question. ${ }^{2}$ As Gregory Mankiw puts it "... if one does not approach the data with a prior view favoring long-run neutrality, one would not leave the data with that posterior. The data's best guess is that monetary shocks leave permanent scars on the economy" (Mankiw (2001), p. 48). This paper provides a new rationale for such empirical findings.

The paper also contributes to a growing theoretical literature explaining how a non-vertical long-run Phillips curve can arise (surveyed, for example, by Orphanides and Solow (1990)). In the context of state-dependent menu costs, see Benabou and Konieczny (1994), Konieczny (1990), Kuran (1986), and Naish (1986). There is also a literature that explains a long-run relation between inflation and employment in terms of fairness, either due to a permanent downward nominal wage rigidity (money illusion) or to departures from rational expectations (Akerlof et al. (1996), Akerlof and Dickens (2007)) and (Akerlof et al. (2000)). Our analysis, by contrast, rests on neither nominal rigidities nor non-rational expectations. ${ }^{3}$

\footnotetext{
${ }^{2}$ For the United States, see for example Beyer and Farmer (2007), Berentsen et al. (2011), Favara and Giordani (2009), Karanassou et al. (2008), Karanassou and Sala (2010)) and Russell and Banerjee (2008) for the United States. For a wider set of industrialized countries, examples include Ball (1997, 1999), Ericson et al. (2001), Dolado et al. (2000), Fair (2000), Fisher and Seater (1993), Gottschalk and Fritsche (2005), King and Watson (1994), Koutsas (1998), Koutsas and Serletis (2003), Koutsas and Veloce (1996), Schreiber and Wolters (2007). Empirical studies that study the Phillips curve in terms of the underlying structural macro models include Ahmed and Rogers (1998), Bullard and Keating (1995), Coenen et al. (2004) and Karanassou et al. (2003, 2005). Concerning developing and emerging countries, see Bae and Ratti (2000) for Argentina and Brazil, by Wallace and Shelley (2004, 2007) for Nicaragua and Mexico, by Puah et al. (2008) for Singapore, and by Chen (2007) for Taiwan.

${ }^{3}$ See also King and Wolman (1996), Ascari (1998), and Graham and Snower (2004), who study the effects of trend inflation in New Keynesian models with nominal frictions and find a long-run relation between the growth rate of money and steady state real aggregates. Amano et al. (2007) discuss the influence of trend inflation on business cycle characteristics such as stochastic means, volatilities, and correlations of macroeconomic aggregates. Based on a second order Taylor approximation around the deterministic steady state they find trend inflation to decrease the mean of output while the variance and the persistence of output and inflation increase. Finally, Graham and Snower (2008) derive a non-vertical Phillips curve from hyperbolic discounting by households.
} 
The notion of fairness that we incorporate in a New Keynesian model is based on inequity aversion. This phenomenon, covering both envy and guilt, is supported by a massive empirical literature. ${ }^{4}$ A large body of empirical studies in the behavioral economics literature argues that relative income substantially matters for one's subjective well-being. ${ }^{5}$ We model inequity aversion along the lines of Fehr and Schmidt (1999) and Bolton and Ockenfels (2000). In our analysis, workers compare their real incomes with the average real income of all the workers, feeling envy when their incomes are relatively low and guilt when they are relatively high. ${ }^{6}$ Envy is stronger that guilt, a finding supported by much empirical evidence. ${ }^{7}$

The novel contribution of this paper is to examine the influence of such inequity aversion on the Phillips curve. As noted, we find that this influence implies a significant, positive long-run relation between inflation and macroeconomic activity for reasonably low inflation rates (say, below 4 percent) and in this context the optimal long-run inflation rate is positive and near 2 percent. This policy implication is noteworthy, since much of the previous literature on optimal monetary policy suggests that prices should decline or remain stable in the long run. According to the Friedman rule, the optimal rate of deflation is equal to the real interest rate. Models that include cash-in-advance constraints, shopping time technologies, and frictions related to the transactional money demand $^{8}$ imply that the optimal inflation rate exceeds the Friedman rule, but is still negative. Other models focusing on the costs of price dispersion ${ }^{9}$ suggest that the optimal inflation rate is zero. Such policy implications are completely at odds with the practice of monetary policy, where positive inflation targets commonly play a central role. In developed countries typically target low inflation rates in an interval from 2 to 3 percent, while developing countries often apply target values which are slightly higher. ${ }^{10}$ There are few theoretical rationales for such practices. ${ }^{11}$ Against this backdrop, we provide a new justification for positive inflation targeting.

\footnotetext{
${ }^{4}$ See, for example, Güth et al. (1982), Forsythe et al. (1994), Roth et al. (1991), Henrich et al. (2001), Karni et al. (2008), and Cappelen et al. (2010, 2011). For surveys of the medical, psychological and neuroeconomic background for this behavior, see Camerer et al. (2005), Loewenstein et al. (2008). See also the neuroeconomic evidence of Sanfrey et al. (2003).

${ }^{5}$ For example, Argyle $(1972,1989)$, Easterlin $(1974,1995)$, Kapteyn and Van Herwaarden (1980), van de Stadt et al. (1985), Scitovsky (1992), Clark and Oswald (1996), Solnick and Hemenway (1998), Blanchflower and Oswald (2004), and Layard et al. (2009)). For a thorough survey on the theoretical and empirical literature of the impact of level and relative income on happiness refer to Clark et al. (2008).

${ }^{6}$ This idea draws on theory developed by the psychologists Homans (1961), Adams (1965) and Walster et al. (1978).

${ }^{7}$ See, for example, Jaques $(1956,1961)$, Messik and Sentis (1979), and Loewenstein et al. (1989)

${ }^{8}$ For example, King and Wolman (1996), Kahn et al. (2003), and Schmitt-Grohé and Uribe (2007, 2010), Aruoba and Schorfheide (2011) .

${ }^{9}$ For example, Galí (2003) and Woodford (2003).

${ }^{10}$ See, for example, Roger and Stone (2005) and Carare and Stone (2006).

${ }^{11} \mathrm{An}$ exception is Graham and Snower (2011), showing that optimal inflation is positive in the presence of hyperbolic discounting by households. See also Fagan and Messina (2009) and Coibion et al. (2010).
} 


\section{The Model Economy}

As noted, we incorporate inequity aversion into a standard dynamic stochastic general equilibrium model with nominal rigidities and positive trend inflation. Firms are perfectly competitive, while households are monopolistic competitors. Workers are infinitely lived and located on the unit interval. Wages are fixed according to the Calvo (1983) nominal contract scheme. ${ }^{12}$ The government prints money, issues riskless bonds, and rebates seignorage gains in equal shares to workers as a lump sum. It conducts monetary policy by controlling the growth rate of nominal money supply $M_{t+1} / M_{t}$, which determines long-run inflation ${ }^{13}$ $\pi_{t+1}$.

\subsection{Firms}

We assume a large number of identical firms. Firms produces a homogenous good according to a Dixit and Stiglitz (1977) CES production function with differentiated labor $n_{j}$ as single input.

$$
y_{t}=\left[\int_{0}^{1} n_{j, t}^{\frac{\theta-1}{\theta}} \mathrm{d} j\right]^{\frac{\theta}{\theta-1}}
$$

The parameter $\theta$ denotes the elasticity of substitution between the different labor types and $y_{t}$ is output. Cost minimization subject to the firms production function (1) yields the firms' demand function for the individual labor type

$$
n_{j, t+i}=\left(\frac{w_{j, t}}{(1+\pi)^{i}}\right)^{-\theta} y_{t+i},
$$

where $w_{j, t}$ is the period- $t$ real value of household $j^{\prime}$ s nominal contract wage set in $t$. Due to perfect competition in the product market, firms take wages and prices as given and produce output at which the price equals marginal cost. Thus the firms' markup is zero and the aggregate real wage is constant and equal to unity.

\subsection{Workers}

Workers are monopolistic competitors, maximizing the utility subject to the labor demand curves (2) that they face. Wages are fixed according to the

\footnotetext{
${ }^{12}$ In a subsequent paper, we also apply the Taylor (1979) staggered contracts scheme and show that the results are quantitatively and qualitatively very similar across both approaches.

${ }^{13}$ See Nelson $(2007,2008)$. We choose money growth over an interest rate rule because, as Reynard (2007) shows, the short term interest rate empirically fails to deliver accurate information on subsequent inflation, while monetary aggregates have a much greater explanatory power for the developments of subsequent inflation and output. This view is strongly supported by Favara and Giordani (2009). Karanassou and Sala (2010) argue that money growth captures well the effects of changes in the short term interest rate on inflation, but also covers additional stances of monetary policy such as banking regulations or possible transmission effects of fiscal measures on the yield curve.
} 
Calvo (1983) nominal contract scheme: in every period, a worker has probability $(1-\alpha)$ to be allowed to reset her contract wage. The worker's utility depends positively on consumption $c_{j, t}$ and negatively on labor $n_{j, t}$. In addition, the worker dislikes to have more or less real income than the average. The worker $j$ 's utility function ${ }^{14}$ is

$$
U\left(c_{j}, n_{j}, \mathcal{I}_{j}\right)=c_{j, t}-\zeta \frac{n_{j, t}^{1+\eta}}{1+\eta}-\psi_{j, t} \frac{\mathcal{I}_{j, t}^{2}}{2}
$$

with $I_{j, t}$ being the relative real income position of workers $j$, which is defined as

$$
\mathcal{I}_{j, t+i}=\frac{w_{j, t}}{(1+\pi)^{i}} n_{j, t+i}-\int_{0}^{1} w_{k, t+i} n_{k, t+i} \mathrm{~d} k .
$$

where $w_{k, t+i}$ is the real value of the current wage of all other workers $k$. In the spirit of Bolton and Ockenfels (2000), worker $j$ compares her real income to the average real income of all other workers $j \neq k$. The parameter $\psi_{j, t}$ is an indicator function:

$$
\psi_{j, t}=\left\{\begin{array}{lll}
\varepsilon & \text { for } & \mathcal{I}_{j, t}<0 \\
\gamma & \text { for } & \mathcal{I}_{j, t}>0
\end{array}\right.
$$

where $\varepsilon$ represents envy and $\gamma$ represents guilt, under the standard restrictions $0<\gamma<1$ and $\varepsilon>0$. Furthermore, $\varepsilon=\kappa \gamma$ where $\kappa>1$, a phenomenon known as egocentric bias. ${ }^{15}$

Worker $j$ 's period- $i$ budget constraint is

$$
\begin{aligned}
& c_{j, t+i}+m_{j, t+1+i}+ b_{j, t+1+i}= \\
& \frac{w_{j, t}}{(1+\pi)^{i}} n_{j, t+i}+\frac{R_{t+i} b_{j, t+i}+m_{j, t+i}}{1+\pi}+\Upsilon_{j, t+i},
\end{aligned}
$$

where $m$ and $b$ are real money and bond holdings and $\Upsilon$ are net lump sum transfers from the government to workers. When worker $j$ is allowed to reset her wage, she maximizes her expected utility:

$$
\max _{W_{t}(h)} E_{t} \sum_{i=0}^{\infty}(\alpha \beta)^{i}\left[U\left(C_{j, t+i}\right)-V\left(N_{j, t+i}\right)-Z\left(\mathcal{I}_{j, t+i}\right)\right]
$$

subject to her budget constraint (6) and her labor demand function (2). The optimal wage sets the present value of the marginal disutility of labor (the numerator) equal to the present value of the marginal utility of consumption and the income (the denominator):

$$
w_{j, t}^{*}=\frac{\theta \zeta}{\theta-1} \frac{E_{t} \sum_{i=0}^{\infty}(\alpha \beta)^{i} n_{j, t+i}^{1+\eta}}{E_{t} \sum_{i=0}^{\infty}(\alpha \beta)^{i} \frac{n_{j, t+i}}{(1+\pi)^{i}}-E_{t} \sum_{i=0}^{\infty}(\alpha \beta)^{i} \psi_{j, t+i} \mathcal{I}_{j, t+i} \frac{n_{j, t+i}(1+\pi)^{i}}{i}} .
$$

\footnotetext{
${ }^{14}$ Karni and Safra (2002) derives an additively separable utility function from a set of basic axioms.

${ }^{15}$ Messik and Senits $(1979,1985)$. Egocentric bias can be interpreted as Tversky and Kahneman's (1991) loss aversion in social comparison.
} 
Rearranging equation (8), we obtain the labor supply equation

$\mu_{w} E_{t} \sum_{i=0}^{\infty}(\alpha \beta)^{i} n_{j, t+i}^{1+\eta}=E_{t} \sum_{i=0}^{\infty}(\alpha \beta)^{i} \frac{w_{j, t}^{*} n_{t+i}(h)}{(1+\pi)^{i}}-E_{t} \sum_{i=0}^{\infty}(\alpha \beta)^{i} \psi_{j, t+i} \mathcal{I}_{j, t+i} \frac{w_{j, t}^{*} n_{j, t+i}}{(1+\pi)^{i}}$,

where $\mu_{w}=\frac{\theta \zeta}{\theta-1}$.

\subsection{The General Equilibrium}

The government prints money $m$, issues bonds $b$ and gives direct transfers $\Upsilon$ to the workers. The government's budget constraint is

$$
m_{t+1+i}+b_{t+1+i}=R_{t+i} b_{t+i}+m_{t+i}+\Upsilon_{t+i} .
$$

The product market clears:

$$
c_{t}=y_{t} .
$$

Aggregate labor is

$$
n_{t}=\int_{0}^{1} n_{j, t} \mathrm{~d} j
$$

The aggregate wage index is

$$
w_{t}=\left[\int_{0}^{1} w_{j, t}^{1-\theta} \mathrm{d} j\right]^{\frac{1}{1-\theta}}
$$

Since we focus on the long-run relations between inflation and real variables, we consider the behavior of economic agents in the symmetric steady state. By the aggregate wage index (13) in the steady state, the optimal reset wage (i.e. the real wage in the time period when the wage is reset) is

$$
w^{*}=\left[\frac{1-\alpha}{1-\alpha(1+\pi)^{\theta-1}}\right]^{\frac{1}{\theta-1}} .
$$

The model contains three equations and three variables. The equations comprise the reset wage (14), the labor supply (8), and the labor demand (2). The variables are the reset wage, aggregate employment and aggregate output $\left\{w^{*}, n, y\right\}$.

We solve the model numerically, along the following simple lines. The reset wage (14) follows directly from the calibration. Substituting this into the labor supply equation (8) yields the steady-state labor supply. Finally, the downward sloping labor demand curve (2) together with the reset wage enables us to solve for aggregate output. 


\begin{tabular}{lcc}
\hline \hline Parameter & Symbol & Value \\
\hline Interest rate & $R$ & $4 \%$ \\
Calvo probability & $\alpha$ & 0.75 \\
Elasticity of labor Substitution & $\theta$ & 5 \\
implying wage markup & & $25 \%$ \\
Elasticity of labor supply & $\nu$ & 4 \\
implying an inverse labor supply elasticity & $\eta$ & 0.25 \\
Envy & $\varepsilon$ & 0.85 \\
Guilt & $\gamma$ & 0.32 \\
Labor weight in utility function & $\zeta$ & 1.05 \\
implying share of work in steady state & & $33 \%$ \\
\hline \hline
\end{tabular}

Table 1: Base Calibration

\subsection{Calibration}

We calibrate the model according to standard values in the literature. The annual interest rate is 4 percent, equivalent to a quarterly discount factor $\beta=$ 0.99. Following Talyor (1999), nominal wages as asssumed to remain fixed for one year, on average. Given that the Calvo pricing scheme follows a poisson process, this average duration is generated by a Calvo parameter $\alpha=0.75$, representing the probability that the nominal wage remains unchanged during the period of analysis. The elasticity of substitution among the different types of labor is $\theta=5$, implying a steady state wage markup of $25 \%$, supported by Graham and Snower (2011) and close to values reported by Ascari (2000), Erceg et al. (2000), and Galí et al. (2011). The parameter $\eta$ denotes the inverse of the labor supply elasticity in the zero inflation steady state. ${ }^{16}$ Following Yun (1996) and empirical evidence from Imai and Keane (2004) and Ransom and Sims (2010), we set the elasticity of labor supply to $\nu=4$, implying that $\eta=0.25$. Furthermore, following Ascari and Merkl (2009), the weight of labor in the utility function $\zeta=1.05$ is chosen so that workers work approximately one-third of their available time endowment in the zero inflation steady state.

Finally, we calibrate the parameters governing envy and guilt in accordance with recent experimental evidence. Based on the results from the experimental literature on ultimatum games, Fehr and Schmidt (1999) derive a distribution for the envy and guilt paramters. Averaging the distribution yields $\gamma=0.32$ and $\varepsilon=0.85$. These parameter values imply that envy times stronger than guilt by a factor is $\kappa=2.7$, identical to that supported by Loewenstein et al. (1989). ${ }^{17}$ Table 1 summarizes our base calibration.

\footnotetext{
${ }^{16}$ Blundell and MaCurdy (1999) and Domeij and Flodén (2006) show that $\nu$ is the intertemporal elasticity of labor supply. In particular, this elasticity measures the reaction of labor supply to an intertemporal reallocation of wages, given a constant marginal utility of wealth. A formal proof that $\eta=\nu^{-1}$ holds in the zero inflation steady state can also be found in the appendix.

${ }^{17}$ The authors find the disadvantageous part of the utility function to be approximately 2.7 times as steep as the advantageous part for neutral relationships.
} 


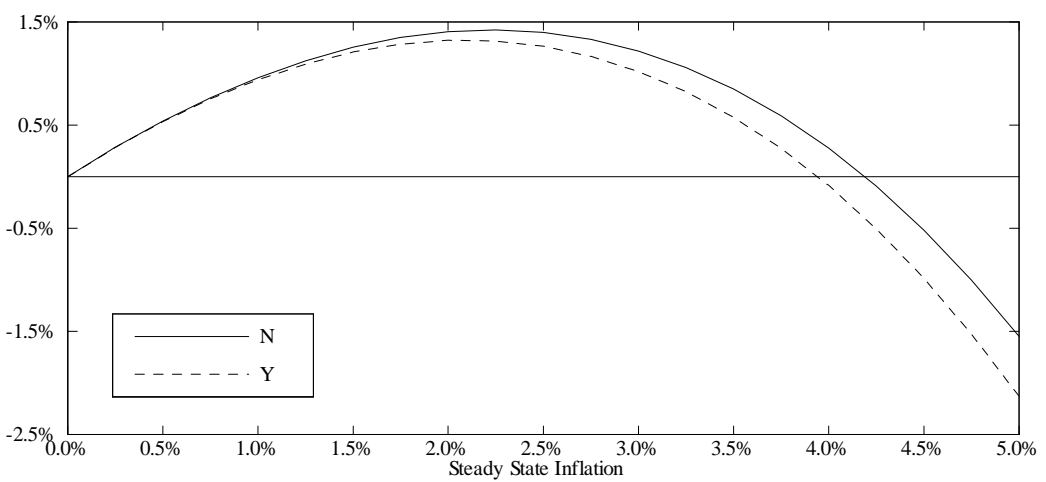

Figure 1: Relation of Inflation to Real Variables

\section{Results}

Figure 1 presents the Phillips curve for the base calibration given in Table 1. On the vertical axis we show the deviations of aggregate employment and output from their respective values at the zero inflation steady state. The horizontal axis measures the steady state inflation rate. ${ }^{18}$ This figure implies that monetary policy has substantial long-run real effects. Expansionary monetary policy that raises inflation from $\pi=0 \%$ to $\pi=2 \%$ is associated with an increase in aggregate employment by 1.40 percent and in aggregate output by 1.32 percent. (As we will show in Section 4.2, the positive relation between inflation and macroeconomic activity is almost entirely driven by the influence of envy and guilt.) The expansionary effect of monetary policy declines as the inflation rate rises. For inflation rates above around $\pi=2.25 \%$, further increases in the rate of money growth lead to reduced aggregate employment and output.

\subsection{Intuition}

In our analysis, there are four channels whereby monetary policy affects output and employment in the long run.

1. The employment cycling effect: When inflation is positive, the real wage falls over the contract period (since the nominal wage is constant over the contract period while the price level rises). Under Calvo wage staggering, different workers reset their nominal wages at different times. For those workers that have recently reset their nominal wages, the real wage is relatively high; whereas those workers that have not done so, the real

\footnotetext{
${ }^{18}$ From Ascari (2004), Amano et. al (2007), and Bakhshi et. al (2007), we know that the Calvo staggering scheme is inadequate for steady state inflation rates exceeding $5 \%$. Therefore, we restrict ourselves to inflation rates up to $5 \%$.
} 
wage is relatively low. In short, inflation is accompanied by fluctuations of relative wages. These fluctuations lead to fluctuations in relative employment rates across workers, as firms substitute cheap labor for expensive labor. Since different workers are imperfect substitutes in production, this substitution is inefficient. The greater is the inflation rate, the greater is the amount of labor substitution and, due to the resulting inefficiency, the lower is aggregate output. In short, employment cycling implies an inverse relation between inflation and macroeconomic activity.

2. The labor smoothing effect: The greater the inflation rate, the more the worker's labor supply varies over the cycle. Workers dislike variable labor supply trajectories, since their marginal disutility of labor rises with labor supplied. Thus a rise in inflation leads to a rise in the average real reservation wage over the contract period and thereby to a fall in employment and output. So labor smoothing also yields an inverse relation between inflation and macroeconomic activity.

3. The envy-guilt effect: Workers experience relatively low incomes early in the contract period and relatively high incomes later. ${ }^{19}$ Thus they experience envy early on. To reduce their disutility from envy, they reduce their average wage so as to increase their average employment. Conversely, they experience guilt later in the contract period, leading them to reduce average employment. But since envy is stronger than guilt, average employment rises. The greater is the inflation rate, the greater is the associated employment and output. Thereby the envy-guilt effect generates a positive relation between inflation and macroeconomic activity.

4. The discounting effect: As noted, at the beginning of the contract period the worker's real wage is relatively high and his employment is relatively low, and conversely later on. The worker has a constant rate of time preference, and thus future utilities are discounted more heavily than present utilities. So the relatively high marginal disutilities of work occuring late in the contract period are discounted more heavily than the relatively low marginal disutilities of work occuring earlier. Accordingly, the discounting effect leads households to supply more labor. Furthermore, guilt (felt late in the contract period) is more heavily affected by discounting than envy (felt early in the contract period). Since guilt reduces labor supply while envy stimulates it, the discounting effect leads to a further increase in labor supply.

Needless to say, the latter discounting effect is complementary with the envyguilt effect. This complementarity is illustrated in Figure 2, where the upper two Phillips curves portray the relation between inflation (on the horizontal axis)

\footnotetext{
${ }^{19}$ Since workers are monopolistic competitors in the labor market, the elasticity of labor demand is greater than unity at the utility-maximizing employment level. Thus the relatively high real wages early in the contract period are associated with relatively low wage incomes.
} 


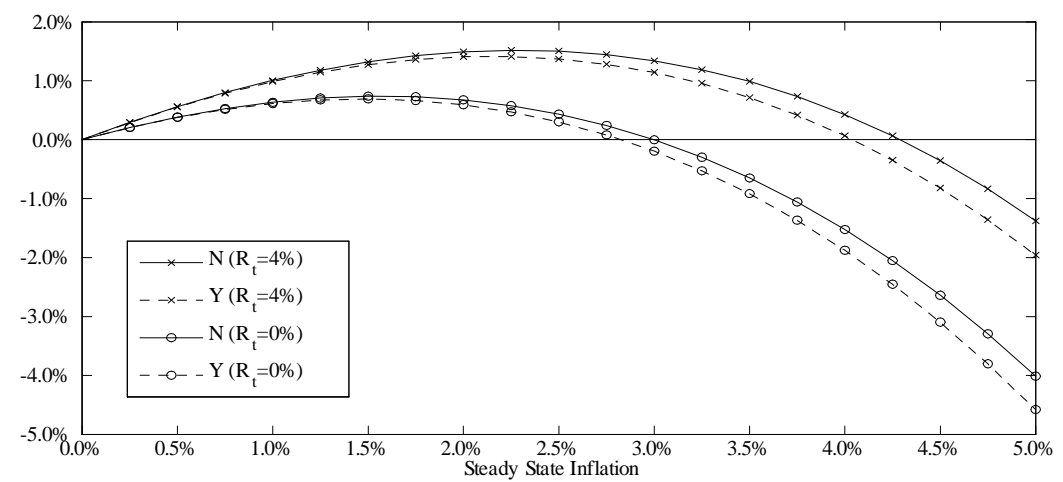

Figure 2: The Complementarity between the Discounting and Envy-Guilt Effects

and employment and output (on the vertical axis) in the presence of both the discounting and envy-guilt effects (as well as the other effects above), whereas the lower two Phillips curves portray this relation in the absence of the discounting effect. The vertical difference measures the size of the complementarity between the discounting effect and the envy-guilt effect (with respect to employment and output).

\subsection{Sensitivities}

Figure 3 shows the sensitivity of the Phillips curve with respect to a range of values for the envy and guilt parameters that have been found in the literature. Holding egocentric bias constant $(\kappa$, representing the relation between envy and guilt: $\varepsilon=\kappa \gamma$ ), the left panel of Figure 3 shows the Phillips curve for the following values of guilt parameter: $\gamma \in(0.24 ; 0.32 ; 0.39)$. Whereas our base case is $\gamma=0.32$, the value $\gamma=0.24$ was supported by Fehr and Schmidt (2003) and the value $\gamma=0.39$ was found by Goeree and Holt (2000). ${ }^{20}$ Figure 3 shows, not surprisingly, that when the guilt and envy effects strengthen the positive long-run effect of monetary policy on output and employment increases.

The right panel of Figure 3 indicates that this positive effect rises with the degree of egocentric bias, i.e. the greater the envy associated with any given level of guilt, the more monetary policy stimulates output and employment in the long run. This result is also not surprising in the light of the analysis above. The figure shows the Phillips curve for the following values of the egocentric

\footnotetext{
${ }^{20}$ Goeree and Holt (2000) estimate the Fehr and Schmidt paramters with experimental data from a two stage-ultimatum game. Support for their estimates comes from Blanco et al. (2011), who apply the same estimation methodology but resort to observations obtained from utlimatum games, dictator games, public goods games, and prisoner's dilemma games. They find the value $\gamma=0.38$.
} 

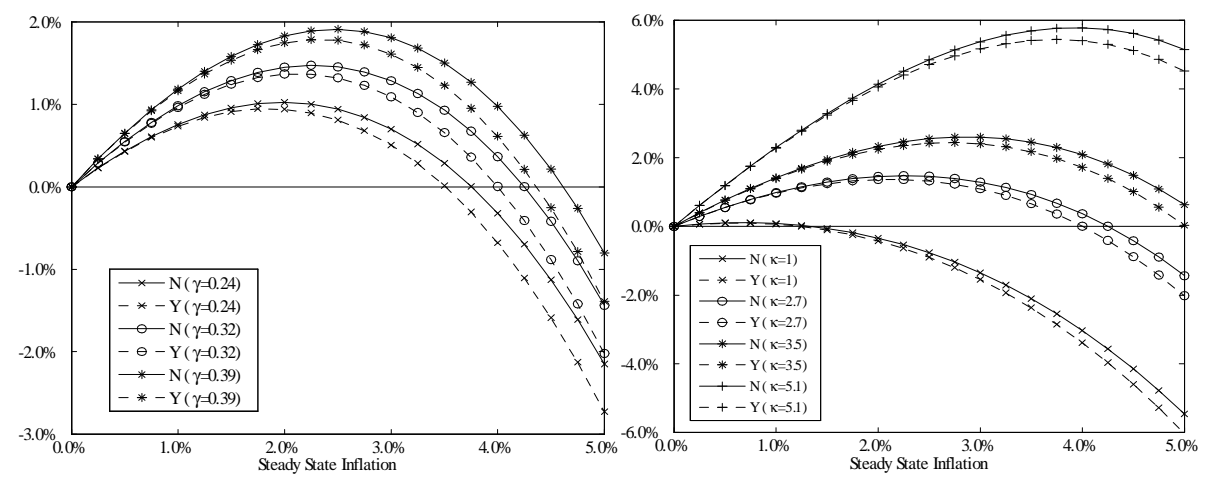

Figure 3: Sensitivity with respect to guilt parameters

bias parameter: $\kappa \in(1 ; 2.7 ; 3.5 ; 5.1)$, where our base case is $\kappa=2.7$. With the exception of $\kappa=1$, all values of the parameters were found in Loewenstein at al. (1989). In particular, while $\kappa=2.7$ was found for a neutral relationship between the judging subject and her reference subject, Loewenstein et al. (1989) find that $\kappa=3.5$ and $\kappa=5.1$ to apply to positive and negative relationship environments, respectively. Moreover, to highlight the importance of the egocentric bias, Figure 3 also displays the results for $\kappa=1$, i.e. in the abscence of any egocentric bias. In this case, the envy and guilt effects play a negligible role and therefore, monetary policy has no substantial positive implications for long-run output and employment. This result holds irrespective of the value of $\gamma$.

Figure 4 shows the sensitivity of the Phillips curve with respect to reasonable values for the labor supply and labor substitution elasticities $\nu=\frac{1}{\eta}$ and $\theta$. The left panel of Figure 4 juxtaposes Phillips curves for the labor supply elasticities $\nu \in(1.5 ; 4 ; 9)$, where our base case is $\nu=4(\eta=0.25)$. The higher labor supply elasticitiy $\nu=9(\eta=0.11)$ was estimated by Abowd and Card (1989) and the lower value $\nu=1.5(\eta=0.66)$ was found by Mulligan (1998) and Heckman et al. (1998). The latter is very close to the values chosen by Rotemberg and Woodford (1996) and Hansen and Wright (1992) in their theoretical contributions. As is apparent from the left panel of Figure 4, the lower the labor supply elasticity (i.e. the higher $\eta$ ), the smaller the effectiveness of monetary policy with respect to aggregate employment and output. Intuitively, the greater the convexity of utility with respect to labor, the more aversive are households to a nonsmooth path of labor supply and therefore, the stronger is the labor smoothing effect. ${ }^{21}$ As discussed above, the labor smoothing effect raises the average real reservation wage, thereby reducing employment and output. Consequently, the Phillips curve shifts downwards.

${ }^{21}$ Furthermore, the higher $\eta$, the larger the weight of disutility of labor in the utility function 

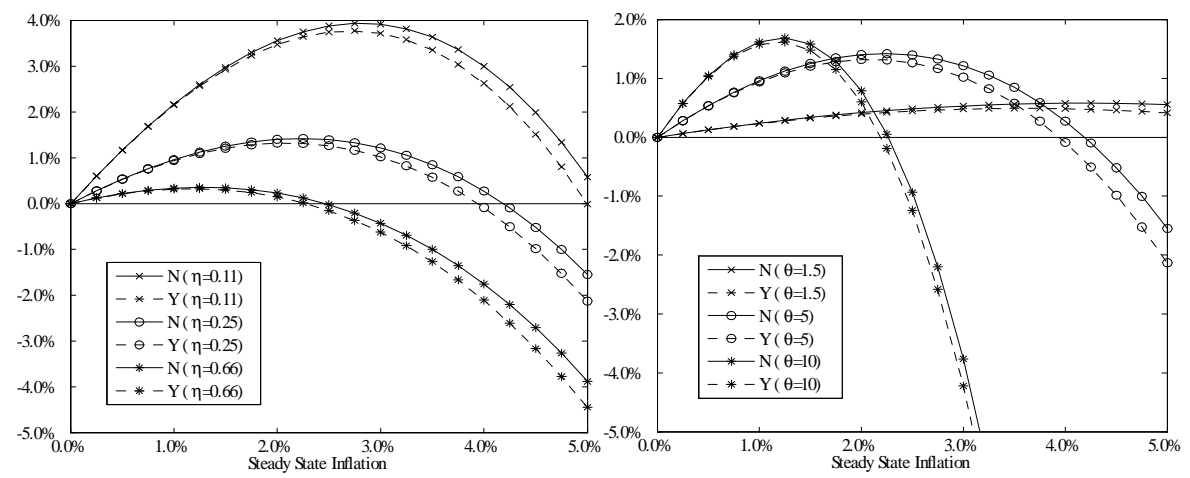

Figure 4: Sensitivity with respect to elasticities

The right panel of Figure 4 shows how the long-run Phillips curve is affected by the degree of labor substitutability over the interval $\theta \in(1.5 ; 5 ; 10)$. The higher the value $\theta$, the more substitutable are the labor types. We contrast our base case $\theta=5$ with a very low degree of substitutability $\theta=1.5$ as estimated by Ciccone and Peri (2005) and a high degree of substitutability $\theta=10$ as found in Fagan and Messina (2009). ${ }^{22}$ As the right panel of Figure 4 indicates, the more substitutable labor types are, the greater the real effects of monetary policy, but over a narrower range. Intuitively, raising the substitutability of labor types has three effects on aggregate. First, it reduces the inefficiencies from labor substitution, so that for a given the amount of employment cycling, output increases. Second, labor substitution becomes cheaper, increasing the incentive for employment cycling, so that output decreases ${ }^{23}$ (ceteris paribus). Third, the increase in employment cycling raises the dispersion of incomes, thereby eliciting more envy and guilt. Since the envy effect is greater than the guilt effect, aggregate output increases (ceteris paribus). As is apparent from the right panel of Figure 4, the positive effects on output (particularly from the envy effect $)^{24}$ are dominant at low inflation rates, whereas the negative effects on output (from additional employment cycling) are dominant at higher inflation

$\zeta$. For $\eta=0.66, \zeta$ increases from 1.05 to 1.65 , while it decreases to 0.9025 for $\eta=0.11$.

${ }^{22}$ On the basis on various country studies, Aidt and Tzannatos (2002) summarize that the average wage markup in industrialized as well as in developing countries lies in the intervall between 10 and $25 \%$, which implies $5 \leq \theta \leq 10$. The low value found by Ciccone and Peri (2005) arises from the fact that they explicitely estimate the markup for high skilled workers over low skilled workers.

${ }^{23}$ Employment cycling has a direct, negative effect on output, as well as an indirect, negative effect via the households' reservation wage (which rises because households' utility falls when employment cycling increases).

${ }^{24} \mathrm{As}$ is apparent from Figure 6 in the appendix, the positive effects of a reduction in inefficiencies from labor substitution are quantitatively negligible (left panel). Therefore, the positive effect can be almost entirely attributed to the envy effect (right panel). 


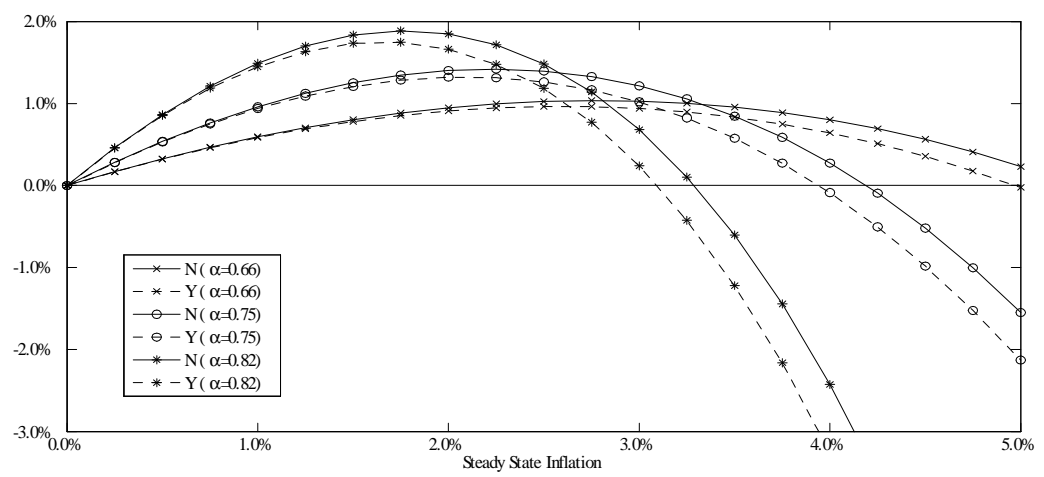

Figure 5: Figure 5: Sensitivity with respect to wage stickiness

rates.

Figure 5 shows the the Phillips curve for different wage stickiness parameters over the range $\alpha \in(0.66 ; 0.75 ; 0.88)$. While in our base calibration wages change on average once a year $(\alpha=0.75)$, Barattieri et al. (2010) find wages to be a little less flexible, i.e. wages change on average every six quarters $(\alpha=0.82)$. Christiano et al. (2005) estimate wages to be sticky for approximately half a year $(\alpha=0.66)$. Analogously to the previous figure, Figure 5 indicates that the stickier wages are, the more effective is monetary policy, but over a narrower range. Intuitively, the stickier wages are, the larger is real wage dispersion and thus the larger is real income dispersion. Consequently, there is more envy and guilt, and since the envy effect is strong, output increases. On the other hand, a larger real wage dispersion implies more labor substitution, which promotes the employment cycling and thereby reduces output. The envy effect dominates at low inflation rates, whereas the employment cycling effects dominates at high inflation rates.

\section{Optimal Monetary Policy}

In the long run, the optimal rate of money growth (equal to the optimal inflation rate) maximizes the lifetime utility of the representative household:

$$
\max _{1+\pi} U=\sum_{i=0}^{\infty}(\alpha \beta)^{i}\left[c_{j, t+i}-\zeta \frac{n_{j, t+i}^{1+\eta}}{1+\eta}-\psi_{j, t+i} \frac{\mathcal{I}_{j, t+i}^{2}}{2}\right]
$$

subject to the labor demand contraint (2), the labor supply constraint (8), and the reset wage (14).

The following table presents the optimal inflation rates for our base calibration, as well as for other values of the envy-guilt parameters. Recalling that in 


\begin{tabular}{cccc}
\hline \hline & $\gamma=0.24$ & $\gamma=0.32$ & $\gamma=0.39$ \\
\hline$\kappa=2.7$ & $1.69 \%$ & $1.80 \%$ & $1.92 \%$ \\
$\kappa=3.5$ & $1.97 \%$ & $2.16 \%$ & $2.30 \%$ \\
$\kappa=5.1$ & $2.47 \%$ & $2.76 \%$ & $2.97 \%$ \\
\hline \hline
\end{tabular}

Table 2: Welfare with respect to envy and guilt

the base case $\kappa=2.7$ and $\gamma=0.32$, we find that optimal inflation is slightly below 2 percent in our base calibration. The higher value of the guilt parameter (with constant egocentric bias) implies a slightly higher optimal inflation rate, and conversely for a lower value of the guilt parameter. Furthermore, greater egocentric bias (with a constant guilt parameter) implies higher optimal inflation, and conversely for less egocentric bias.

The intuition underlying these results is straightforward. The optimal inflation rate is positive for two reasons: (1) When the inflation rate is zero, output and employment are inefficiently low, since workers are monopolistic competitors in the labor market. (2) Due to the envy-guilt and discounting effects, higher inflation is associated with greater output and employment, over a range of low inflation rates. On this account, a positive long-run rate of money growth is able to reduce the inefficiency from monopolistic competition.

More precisely, when the money growth rate rises above zero, it affects welfare in the following ways: (1) it reduces the inefficiency from monopolistic competition and thereby raises the utility from consumption, (2) it raises the inefficiency from employment cycling, (3) it increases the disutility of labor due to a more volatile labor trajectory and (4) it increases the disutility from envy and guilt. While the first influence enters the utility function linearly in output, the other influences grow exponentially as inflation increases output and employment. Thus the first influence dominates at low inflation rates, whereas the latter influences dominate at higher inflation rates.

Needless to say, the inefficiency from monopolistic competition can be reduced in ways other than expansionary monetary policy and these other ways may have more favorable welfare effects than expansionary monetary policy. But the overarching implication of our analysis is this. If, for whatever reason, ${ }^{25}$ the equilibrium levels of output and employment are inefficiently low after the government has implemented all its fiscal and structural policies then expansionary monetary policy can be welfare-promoting by reducing the residual inefficiency.

shows how the optimal inflation rate varies with respect to different values ${ }^{26}$ for the intertemporal and intratemporal labor substitution elasticities $\eta$ and $\theta$, respectively, and the degree of wage stickiness $\alpha$.

Table 3The first two rows of Table 3 indicate that the optimal inflation rate is negatively related to the inverse of the labor supply elasticity $\eta=\nu^{-1}$.

\footnotetext{
${ }^{25}$ There are of course many conceivable reasons why output and employment may be too low, such as distortionary taxes, efficiency-wage, insider-outsider, or union-power effects.

${ }^{26}$ We use the values chosen in the sensitivity analysis.
} 


\begin{tabular}{lccc}
\hline \hline & $\gamma=0.24$ & $\gamma=0.32$ & $\gamma=0.39$ \\
\hline alternative $\eta:$ & & & \\
$\eta=0.11$ & $2.31 \%$ & $2.53 \%$ & $2.67 \%$ \\
$\eta=0.66$ & $0.92 \%$ & $0.97 \%$ & $1.01 \%$ \\
alternative $\theta:$ & & & \\
$\theta=1.5$ & $3.23 \%$ & $3.30 \%$ & $3.45 \%$ \\
$\theta=10$ & $0.96 \%$ & $0.97 \%$ & $0.99 \%$ \\
alternative $\alpha:$ & & & \\
$\alpha=0.66$ & $1.93 \%$ & $2.14 \%$ & $2.18 \%$ \\
$\alpha=0.82$ & $1.51 \%$ & $1.59 \%$ & $1.65 \%$ \\
\hline \hline
\end{tabular}

Table 3: Welfare with respect to model parameters

Intuitively, when the convexity of utility with respect to labor rises, the disutility of work increases relative to the utility of consumption. Since the benefits of extra output decline more rapidly, reducing the optimal inflation rate.

The next two rows of Table 3 show that the greater the substitutability among labor types, the lower is the optimal inflation rate. The degree of substitutability measures the market power of the different worker types. The lower $\theta$, the higher is the market power of each labor type, and thus the larger is the inefficiency from monopolistic competition, implying a lower optimal inflation rate.

Finally, the last two rows of Table 3 indicate that the greater is the degree of wage stickiness, the lower is the optimal inflation rate. Intuitively, the greater is the degree of wage stickiness the more dispersed is the real wage distribution and the greater is employment cycling. This reduces utility due to the inefficiency of employment cycling, households' aversion to volatile incomes, and the envy and guilt effects. Thus the optimal inflation rate falls.

\section{Conclusion}

We have shown that, in the presence of staggered, monopolistically competitive nominal wage contracts, inequity aversion can generate a positive long-run tradeoff between inflation and macroeconomic activity. Under these circumstances, our analysis implies that expansionary monetary policy - leading to a low, positive inflation rate - is socially optimal. For our base calibration, the optimal inflation rate is just under 2 percent.

Our analysis is meant to help bridge the gap between monetary theory and central banking practice. In contrast to much of the recent literature on monetary policy, we provide a rationale for targeting inflation at a low, positive rate.

In our analysis, the relation between inflation and macroeconomic activity is the outcome of four phenomena: employment cycling, labor supply variability, discounting and envy-guilt effects. The first two phenomena imply an inverse 
relation between inflation and macroeconomic activity, whereas the last two are complementary and imply a positive relation. Furthermore, the last two dominate at low inflation rates, whereas the first two dominate at high inflation rates. Consequently, the Phillips curve is backward-bending, so that increases in money growth lead to higher employment and output at low inflation, but to lower employment and output at high inflation.

In this context, the role of optimal monetary policy is to reduce inefficiencies that generate suboptimally low employment and output. This provides a rationale for a low, positive long-run inflation target.

\section{References}

Abowd, J. M. and D. Card (1989). On the covariance structure of earnings and hours changes. Econometrica 57(2), 411-445.

Adams, J. S. (1965). Inequity in social exchange. In Advance in Experimental Psychology, Volume 2, pp. 267-299. New York: Academic Press.

Ahmed, S. and J. H. Rogers (1998). Inflation and the great ratios: longterm evidence from the U.S. International Finance Discussion Papers 628, Board of Governors of the Federal Reserve System (U.S.).

Aidt, T. and Z. Tzannatos (2002). Unions and Collective Bargaining: Economic Effects in a Global Environment. The World Bank, Washington D.C.

Akerlof, G. A., W. R. Dickens, and G. L. Perry (1996). The macroeconomics of low inflation. Brookings Papers on Economic Activity 27(1996-1), 1-76.

Akerlof, G. A. and W. T. Dickens (2007). Unfinished business in the macroeconomics of low inflation: A tribute to George and Bill by Bill and George. Brookings Papers on Economic Activity 38(2007-2), 31-48.

Akerlof, G. A., W. T. Dickens, and G. L. Perry (2000). Near-rational wage and price setting and the long-run phillips curve. Brookings Papers on Economic Activity 31(2000-1), 1-60.

Amano, R., S. Ambler, and N. Rebei (2007). The macroeconomic effects of nonzero trend inflation. Journal of Money, Credit and Banking 39(7), 1821-1838.

Argyle, M. (1972). The Social Psychology of Work. Tablinger Publishing Company, New York.

Argyle, M. (1989). The Psychology of Happiness. Routledge, London.

Aruoba, S. B. and F. Schorfheide (2011). Sticky prices versus monetary frictions: An estimation of policy trade-offs. American Economic Journal: Macroeconomics 3(1), 60-90.

Ascari, G. (1998). Superneutrality of money in staggered wage-setting models. Macroeconomic Dynamics 2(03), 383-400. 
Ascari, G. (2000). Optimising agents, staggered wages and persistence in the real effects of money shocks. Economic Journal 110(465), 664-686.

Ascari, G. (2004). Staggered prices and trend inflation: Some nuisances. Review of Economic Dynamics 7(3), 642-667.

Ascari, G. and C. Merkl (2009). Real wage rigidities and the cost of disinflations. Journal of Money, Credit and Banking 41(2-3), 417-435.

Bae, S.-K. and R. A. Ratti (2000). Long-run neutrality, high inflation, and bank insolvencies in Argentina and Brazil. Journal of Monetary Economics 46(3), 581-604.

Bakhshi, H., H. Khan, P. Burriel-Llombart, and B. Rudolf (2007). The new keynesian phillips curve under trend inflation and strategic complementarity. Journal of Macroeconomics 29(1), 37-59.

Ball, L. (1997). Disinflation and the NAIRU. In C. D. Romer and D. H. Romer (Eds.), Reducing Inflation: Motivation and Strategy. University of Chicago Press.

Ball, L. (1999). Aggregate demand and long-term unemployment. Brookings Papers on Economic Activity 30(2), 189-252.

Barattieri, A., S. Basu, and P. Gottschalk (2010). Some evidence on the importance of sticky wages. NBER Working Papers 16130, National Bureau of Economic Research, Inc.

Benabou, R. and J. D. Konieczny (1994). On inflation and output with costly price changes: A simple unifying result. American Economic Review 84 (1), 290-297.

Berentsen, A., G. Menzio, and R. Wright (2011). Inflation and unemployment in the long run. American Economic Review 101(1), 371-98.

Beyer, A. and R. E. Farmer (2007). Natural rate doubts. Journal of Economic Dynamics and Control 31(3), 797-825.

Blanchflower, D. G. and A. J. Oswald (2004). Well-being over time in Britain and the USA. Journal of Public Economics 88 (7-8), 1359-1386.

Blanco, M., D. Engelmann, and H.-T. Normann (2011). A within-subject analysis of other-regarding preferences. Games and Economic Behavior 72 (2), 321-338.

Blundell, R. and T. Macurdy (1999). Labor supply: A review of alternative approaches. In O. Ashenfelter and D. Card (Eds.), Handbook of Labor Economics, Volume 3 of Handbook of Labor Economics, Chapter 27, pp. 1559-1695. Elsevier.

Bolton, G. E. and A. Ockenfels (2000). ERC: A theory of equity, reciprocity, and competition. American Economic Review 90(1), 166-193.

Bullard, J. and J. W. Keating (1995). The long-run relationship between inflation and output in postwar economies. Journal of Monetary Economics 36(3), 477-496. 
Calvo, G. A. (1983). Staggered prices in a utility-maximizing framework. Journal of Monetary Economics 12(3), 383-398.

Camerer, C. F., G. F. Loewenstein, and D. Prelec (2005). Neuroeconomics: How neuroscience can inform economics. Journal of Economic Literature 43(1), 9-64.

Cappelen, A. W., K. Nygaard, E. Sörensen, and B. Tungodden (2010, November). Efficiency, equality and reciprocity in social preferences: A comparison of students and a representative population. Discussion Paper Series in Economics 28/2010, Department of Economics, Norwegian School of Economics.

Cappelen, A. W., K. Nygaard, E. Sörensen, and B. Tungodden (2011). Social preferences in the lab: A comparison of students and a representative population. CESifo Working Paper Series 3511, CESifo Group Munich.

Carare, A. and M. R. Stone (2006). Inflation targeting regimes. European Economic Review 50(5), 1297-1315.

Chen, S.-W. (2007). Evidence of the long-run neutrality of money: The case of South Korea and Taiwan. Economics Bulletin 3(64), 1-18.

Christiano, L. J., M. Eichenbaum, and C. L. Evans (2005). Nominal rigidities and the dynamic effects of a shock to monetary policy. Journal of Political Economy 113(1), 1-45.

Ciccone, A. and G. Peri (2005). Long-run substitutability between more and less educated workers: Evidence from U.S. states, 1950-1990. The Review of Economics and Statistics 87(4), 652-663.

Clark, A. E., P. Frijters, and M. A. Shields (2008). Relative income, happiness, and utility: An explanation for the easterlin paradox and other puzzles. Journal of Economic Literature 46(1), 95-144.

Clark, A. E. and A. J. Oswald (1996). Satisfaction and comparison income. Journal of Public Economics 61(3), 359-381.

Coenen, G., A. Orphanides, and V. Wieland (2004). Price stability and monetary policy effectiveness when nominal interest rates are bounded at zero. The B.E. Journal of Macroeconomics 0(1).

Coibion, O., Y. Gorodnichenko, and J. F. Wieland (2010, June). The optimal inflation rate in new keynesian models. NBER Working Papers 16093, National Bureau of Economic Research, Inc.

Dixit, A. K. and J. E. Stiglitz (1977). Monopolistic competition and optimum product diversity. American Economic Review 67(3), 297-308.

Dolado, J. J., J. D. López-Salido, and J. L. Vega (2000). Unemployment and inflation persistence in Spain: Are there phillips trade-offs? Spanish Economic Review 2(3), 267-291.

Domeij, D. and M. Floden (2006). The labor-supply elasticity and borrowing constraints: Why estimates are biased. Review of Economic Dynamics $9(2), 242-262$. 
Easterlin, R. A. (1974). Does economic growth improve the human lot? some empirical evidence. In P. A. David and M. W. Reder (Eds.), Nations and Households in Economic Growth: Essays in Honor of Moses Abramovitz. New York: Academic Press.

Easterlin, R. A. (1995). Will raising the incomes of all increase the happiness of all? Journal of Economic Behavior \& Organization 27(1), 35-47.

Erceg, C. J., D. W. Henderson, and A. T. Levin (2000). Optimal monetary policy with staggered wage and price contracts. Journal of Monetary Economics 46(2), 281-313.

Ericsson, N. R., J. S. Irons, and R. W. Tryon (2001). Output and inflation in the long run. Journal of Applied Econometrics 16(3), 241-253.

Fagan, G. and J. Messina (2009). Downward wage rigidity and optimal steadystate inflation. Working Paper Series 1048, European Central Bank.

Fair, R. C. (2000). Testing the nairu model for the United States. The Review of Economics and Statistics 82(1), 64-71.

Favara, G. and P. Giordani (2009). Reconsidering the role of money for output, prices and interest rates. Journal of Monetary Economics 56(3), 419430.

Fehr, E. and K. Schmidt (2003). Theories of fairness and reciprocity - evidence and economic applications. In M. Dewatripont, L. P. Hansen, and S. J. Turnovsky (Eds.), Advances in Economics, Volume 1, pp. 208-257. Econometric Society Monographs,Eight World Congress.

Fehr, E. and K. M. Schmidt (1999). A theory of fairness, competition, and cooperation. The Quarterly Journal of Economics 114(3), 817-868.

Fisher, M. E. and J. J. Seater (1993). Long-run neutrality and superneutrality in an arima framework. American Economic Review 83(3), 402-415.

Forsythe, R., J. L. Horowitz, N. E. Savin, and M. Sefton (1994). Fairness in simple bargaining experiments. Games and Economic Behavior 6(3), $347-369$.

Galí, J. (2003). New perspectives on monetary policy, inflation, and the business cycle. In L. H. M. Dewatripont and S. Turnovsky (Eds.), Advances in Economic Theory, Volume 3, pp. 151-197. Cambridge University Press.

Galí, J., F. Smets, and R. Wouters (2011). Unemployment in an estimated new keynesian model. In NBER Macroeconomics Annual 2011, Volume 26, NBER Chapters. National Bureau of Economic Research, Inc.

Goeree, J. K. and C. A. Holt (2000). Asymmetric inequality aversion and noisy behavior in alternating-offer bargaining games. European Economic Review 44(4-6), 1079-1089.

Gottschalk, J. and U. Fritsche (2005). The new keynesian model and the long-run vertical phillips curve: Does it hold for Germany? Discussion Papers of DIW Berlin 521, DIW Berlin, German Institute for Economic Research. 
Graham, L. and D. J. Snower (2004). The real effects of money growth in dynamic general equilibrium. Working Paper Series 412, European Central Bank.

Graham, L. and D. J. Snower (2008). Hyperbolic discounting and the phillips curve. Journal of Money, Credit and Banking 40(2-3), 427-448.

Graham, L. and D. J. Snower (2011, May). Hyperbolic discounting and positive optimal inflation. CEPR Discussion Papers 8390, C.E.P.R. Discussion Papers.

Güth, W., R. Schmittberger, and B. Schwarze (1982). An experimental analysis of ultimatum bargaining. Journal of Economic Behavior $\& 3$ Organization 3(4), 367-388.

Hansen, G. D. and R. Wright (1992). The labor market in real business cycle theory. Quarterly Review, 2-12.

Heckman, J., L. Lochner, and C. Taber (1998). Explaining rising wage inequality: Explanations with a dynamic general equilibrium model of labor earnings with heterogeneous agents. Review of Economic Dynamics 1(1), $1-58$.

Henrich, J., R. Boyd, S. Bowles, C. Camerer, E. Fehr, H. Gintis, and R. McElreath (2001). In search of homo economicus: Behavioral experiments in 15 small-scale societies. American Economic Review 91(2), 73-78.

Homans, G. C. (1961). Social behavior: its elementary forms. New York : Harcourt, Brace \& World.

Imai, S. and M. P. Keane (2004). Intertemporal labor supply and human capital accumulation. International Economic Review 45(2), 601-641.

Jaques, E. (1956). Measurement of Responsibility. A Study of Work, Payment, and Individual Capacity. London: Tavistock Publications.

Jaques, E. (1961). Equitable payment: a general theory of work, differential payment, and individual progress. London: Heinemann.

Kapteyn, A. and F. G. Van Herwaarden (1980). Interdependent welfare functions and optimal income distribution. Journal of Public Economics 14(3), 375-397.

Karanassou, M. and H. Sala (2010). The US inflation-unemployment tradeoff revisited: New evidence for policy-making. Journal of Policy Modeling 32(6), 758-777.

Karanassou, M., H. Sala, and D. J. Snower (2003). The European phillips curve: Does the NAIRU exist? Applied Economics Quarterly 2(876), 93121.

Karanassou, M., H. Sala, and D. J. Snower (2005). A reappraisal of the inflation-unemployment tradeoff. European Journal of Political Economy 21(1), 1-32. 
Karanassou, M., H. Sala, and D. J. Snower (2008). The evolution of inflation and unemployment: Explaining the roaring nineties. Australian Economic Papers 47(4), 334-354.

Karni, E. and Z. Safra (2002). Individual sense of justice: A utility representation. Econometrica 70(1), 263-284.

Karni, E., T. Salmon, and B. Sopher (2008). Individual sense of fairness: an experimental study. Experimental Economics 11(2), 174-189.

Khan, A., R. G. King, and A. L. Wolman (2003). Optimal monetary policy. Review of Economic Studies 70(4), 825-860.

King, R. G. and M. W. Watson (1994). The post-war U.S. phillips curve: a revisionist econometric history. Carnegie-Rochester Conference Series on Public Policy 41(1), 157-219.

King, R. G. and A. L. Wolman (1996). Inflation targeting in a St. Louis model of the 21st century. Proceedings, 83-107.

Konieczny, J. D. (1990). Inflation, output and labour productivity when prices are changed infrequently. Economica 57(226), 201-218.

Koustas, Z. (1998). Canadian evidence on long-run neutrality propositions. Journal of Macroeconomics 20(2), 397-411.

Koustas, Z. and A. Serletis (2003). Long-run phillips-type trade-offs in European Union countries. Economic Modelling 20(4), 679-701.

Koustas, Z. and W. Veloce (1996). Unemployment hysteresis in Canada: An approach based on long-memory time series models. Applied Economics 28(7), 823-831.

Kuran, T. (1986). Price adjustment costs, anticipated inflation, and output. The Quarterly Journal of Economics 101(2), 407-418.

Layard, R., G. Mayraz, and S. Nickell (2009). Does relative income matter? are the critics right? CEP Discussion Papers dp0918, Centre for Economic Performance, LSE.

Loewenstein, G., S. Rick, and J. D. Cohen (2008). Neuroeconomics. Annual Review of Psychology 59, 647-672.

Loewenstein, G. F., L. Thompson, and M. H. Bazerman (1989). Social utility and decision making in interpersonal contexts. Journal of Personality $\mathcal{E}$ Social Psychology 57(3), 426-441.

Mankiw, N. G. (2001). The inexorable and mysterious tradeoff between inflation and unemployment. Economic Journal 111(471), C45-61.

Messick, D. M. and K. P. Sentis (1979). Fairness and preferences. Journal of Experimental Social Psychology 15(4), 418-434.

Messick, D. M. and K. P. Sentis (1985). Estimating social and nonsocial utility functions from ordinal data. European Journal of Social Psychology 15(4), 389-399. 
Mulligan, C. B. (1999). Substition over time: Another look at life-cycle labor supply. In NBER Macroeconomics Annual 1998, volume 13, NBER Chapters, pp. 75-152. National Bureau of Economic Research, Inc.

Naish, H. F. (1986). Price adjustment costs and the output-inflation trade-off. Economica 53(210), 219-230.

Nelson, E. (2007). Comment on: Samuel Reynard's "maintaining low inflation: Money, interest rates, and policy stance". Journal of Monetary Economics 54 (5), 1472-1479.

Nelson, E. (2008). Why money growth determines inflation in the long run: Answering the woodford critique. Journal of Money, Credit and Banking 40(8), 1791-1814.

Orphanides, A. and R. M. Solow (1990). Money, inflation and growth. In B. M. Friedman and F. H. Hahn (Eds.), Handbook of Monetary Economics, Volume 1 of Handbook of Monetary Economics, Chapter 6, pp. 223-261. Elsevier.

Puah, C.-H., M. S. Habibullah, and S. A. Mansor (2008). On the long-run monetary neutrality: Evidence from the SEACEN countries. Journal of Money, Investment and Banking 2, 50-62.

Ransom, M. R. and D. P. Sims (2010). Estimating the firm's labor supply curve in a new monopsony framework: Schoolteachers in Missouri. Journal of Labor Economics 28(2), 331-355.

Reynard, S. (2007). Maintaining low inflation: Money, interest rates, and policy stance. Journal of Monetary Economics 54(5), 1441-1471.

Roger, S. and M. R. Stone (2005). On target? the international experience with achieving inflation targets. IMF Working Papers 05/163, International Monetary Fund.

Rotemberg, J. J. and M. Woodford (1996). Real-business-cycle models and the forecastable movements in output, hours, and consumption. American Economic Review 86(1), 71-89.

Roth, A. E., V. Prasnikar, M. Okuno-Fujiwara, and S. Zamir (1991). Bargaining and market behavior in Jerusalem, Ljubljana, Pittsburgh, and Tokyo: An experimental study. American Economic Review 81(5), 1068-1095.

Russell, B. and A. Banerjee (2008). The long-run phillips curve and nonstationary inflation. Journal of Macroeconomics 30(4), 1792-1815.

Sanfey, A. G., J. K. Rilling, J. A. Aronson, L. E. Nystrom, and J. D. Cohen (2003). The neural basis of economic decision-making in the ultimatum game. Science 300(5626), $1755-1758$.

Schmitt-Grohé, S. and M. Uribe (2007). Optimal inflation stabilization in a medium-scale macroeconomic model. In F. S. Miskin, K. Schmidt-Hebbel, N. L. S. Editor), and K. S.-H. (Se (Eds.), Monetary Policy under Inflation Targeting, Volume 11 of Central Banking, Analysis, and Economic Policies Book Series, Chapter 5, pp. 125-186. Central Bank of Chile. 
Schmitt-Grohé, S. and M. Uribe (2010). The optimal rate of inflation. NBER Working Papers 16054, National Bureau of Economic Research, Inc.

Schreiber, S. and J. Wolters (2007). The long-run phillips curve revisited: Is the NAIRU framework data-consistent? Journal of Macroeconomics 29(2), 355-367.

Scitovsky, T. (1992). The Joyless Economy: The Psychology of Human Satisfaction. New York: Oxford University Press.

Solnick, S. J. and D. Hemenway (1998). Is more always better?: A survey on positional concerns. Journal of Economic Behavior \& Organization 37(3), 373-383.

Taylor, J. B. (1979). Staggered wage setting in a macro model. American Economic Review 69(2), 108-113.

Taylor, J. B. (1999). Staggered price and wage setting in macroeconomics. In J. B. Taylor and M. Woodford (Eds.), Handbook of Macroeconomics, Volume 1 of Handbook of Macroeconomics, Chapter 15, pp. 1009-1050. Elsevier.

Tversky, A. and D. Kahneman (1991). Loss aversion in riskless choice: A reference-dependent model. The Quarterly Journal of Economics 106(4), 1039-1061.

van de Stadt, H., A. Kapteyn, and S. van de Geer (1985). The relativity of utility: Evidence from panel data. The Review of Economics and Statistics 67(2), 179-187.

Wallace, F. H. and G. L. Shelley (2004). Long run neutrality and superneutrality of money: Aggregate and sectoral tests for Nicaragua. EconWPA, Macroeconomics (0402004).

Wallace, F. H. and G. L. Shelley (2007). Long run neutrality of money in Mexico. Economia Mexicana NUEVA EPOCA 0(2), 219-238.

Walster, E., G. W. Walster, and E. Berscheid (1978). Equity: Theory and Research. Boston: Allyn and Bacon.

Woodford, M. (2003). Interest and Prices. Princeton: Princeton University Press.

Yun, T. (1996). Monetary policy, nominal price rigidity, and business cycles. Journal of Monetary Economics 37, 345-370.

Yun, T. (2005). Optimal monetary policy with relative price distortions. American Economic Review 95(1), 89-109. 


\section{Appendix}

\subsection{Steady State Relative Wage}

To calculate the steady state we drop the time indices. The detrended wage index in a Calvo world is given by

$$
w_{t}=\left[(1-\alpha) w_{t}^{* 1-\theta}+\alpha\left(\frac{w_{t-1}}{1+\pi}\right)^{1-\theta}\right]^{\frac{1}{1-\theta}}
$$

In the steady state we drop time indices

$$
w^{1-\theta}=(1-\alpha) w^{* 1-\theta}+\alpha\left(\frac{w}{1+\pi}\right)^{1-\theta}
$$

Grouping terms

$$
\left(1-\alpha(1+\pi)^{\theta-1}\right) W^{1-\theta}=(1-\alpha) W^{* 1-\theta}
$$

and re-arranging yields the optimal relative steady state wage

$$
w_{j}=\left(\frac{1-\alpha}{1-\alpha(1+\pi)^{\theta-1}}\right)^{\frac{1}{\theta-1}} .
$$

\subsection{Wage dispersion}

From aggregate labor and the individual labor demand we get

$$
\begin{aligned}
& n_{t}=\int_{0}^{1} w_{k, t}^{-\theta} y_{t} \mathrm{~d} k, \\
& n_{t}=y_{t} \underbrace{\int_{0}^{1} w_{k, t}^{-\theta} \mathrm{d} k}_{s_{t}}, \\
& n_{t}=s_{t} y_{t} .
\end{aligned}
$$

Furthermore

$$
\begin{aligned}
s_{t} & =\int_{0}^{1} w_{k, t}^{-\theta} \mathrm{d} k \\
& =(1-\alpha) w_{k, t}^{-\theta}+\alpha(1-\alpha)\left(\frac{w_{k, t-1}}{(1+\pi)^{-1}}\right)^{-\theta}+\alpha^{2}(1-\alpha)\left(\frac{w_{k, t-2}}{(1+\pi)^{-2}}\right)^{-\theta}+.(24) \\
& =(1-\alpha) w_{k, t}^{-\theta}+\alpha(1+\pi)^{\theta}\left[(1-\alpha) w_{k, t-1}^{-\theta}+\alpha(1-\alpha)\left(\frac{w_{k, t-2}}{(1+\pi)^{-1}}\right)^{-\theta}+\ldots(25)\right. \\
& =(1-\alpha) w_{k, t}^{-\theta}+\alpha(1+\pi)^{\theta} s_{t-1}
\end{aligned}
$$


which in the steady state is given by

$$
\begin{aligned}
s & =(1-\alpha) w_{k}^{-\theta}+\alpha(1+\pi)^{\theta} s, \\
s & =\frac{(1-\alpha) w_{k}^{-\theta}}{1-\alpha(1+\pi)^{\theta}} .
\end{aligned}
$$

\section{Derivation of Labor Supply Curve}

The worker maximizes utility

$$
\max _{w_{j, t}} E_{t} \sum_{i=0}^{\infty}(\alpha \beta)^{i}\left[U\left(c_{j, t+i}\right)-V\left(n_{j, t+i}\right)-Z\left(\mathcal{I}_{j, t+i}\right)\right]
$$

subject to its budget constraint

$$
\begin{aligned}
& c_{j, t+i}+m_{j, t+1+i}+ b_{j, t+1+i}= \\
& \frac{w_{j, t}}{(1+\pi)^{i}} n_{j, t+i}+\frac{R_{t+i} b_{j, t+i}+m_{j, t+i}}{1+\pi}+\Upsilon_{j, t+1+i} .
\end{aligned}
$$

where $m$ and $b$ are real money and bond holdings and $\Upsilon$ are lump sum transfers from the government to workers and the downward-sloping labor demand

$$
n_{j, t+i}=\left(\frac{w_{j, t}}{(1+\pi)^{i}}\right)^{-\theta} y_{t+i}
$$

and inequity aversion

$$
\mathcal{I}_{j, t+i}=\frac{w_{j, t}}{(1+\pi)^{i}} n_{j, t+i}-\underbrace{\int_{0}^{1} w_{k, t+i} n_{k, t+i} \mathrm{~d} k}_{\mathcal{N}},
$$

where $N$ denotes the average income in the economy. The first order condition of this maximization problem yields

$$
E_{t} \sum_{i=0}^{\infty}(\alpha \beta)^{i}\left[(1-\theta) U_{c} \frac{n_{j, t+i}}{(1+\pi)^{i}}+\theta V_{n} \frac{n_{j, t+i}}{w_{j, t}}-(1-\theta) Z_{\mathcal{I}} \frac{n_{j, t+i}}{(1+\pi)^{i}}\right]=0 .
$$

Re-arranging equation (33) we get

$$
\begin{aligned}
& E_{t} \sum_{i=0}^{\infty}(\alpha \beta)^{i} \theta V_{n} \frac{n_{j, t+i}}{w_{j, t}} \\
&=(\theta-1)\left[E_{t} \sum_{i=0}^{\infty}(\alpha \beta)^{i} \frac{U_{c} n_{j, t+i}}{(1+\pi)^{i}}-E_{t} \sum_{i=0}^{\infty}(\alpha \beta)^{i} \frac{Z_{\mathcal{I}} n_{j, t+i}}{(1+\pi)^{i}}\right] .
\end{aligned}
$$

Rearranging equation (34) with respect to $w_{j, t}$ yields

$$
w_{j, t}=\frac{\theta}{\theta-1} \frac{E_{t} \sum_{i=0}^{\infty}(\alpha \beta)^{i} V_{n} n_{j, t+i}}{E_{t} \sum_{i=0}^{\infty}(\alpha \beta)^{i} U_{c} \frac{n_{j, t+i}}{(1+\pi)^{i}}-E_{t} \sum_{i=0}^{\infty}(\alpha \beta)^{i} Z_{\mathcal{I}} \frac{n_{j, t+i}}{(1+\pi)^{i}}} .
$$


From the utility function

$$
U\left(c_{j}, n_{j}, \mathcal{I}_{j}\right)=c_{j, t}-\zeta \frac{n_{j, t}^{1+\eta}}{1+\eta}-\psi_{j, t} \frac{\mathcal{I}_{j, t}^{2}}{2}
$$

we obtain the first order conditions $V_{n}, U_{c}$, and $Z_{\mathcal{I}}$ :

$$
\begin{aligned}
V_{n} & =\zeta n_{j, t+i}^{\eta}, \\
U_{c} & =1, \\
Z_{\mathcal{I}} & =\psi_{j, t+i} \mathcal{I}_{j, t+i}
\end{aligned}
$$

Plugging equations (37), (38), and (39) into (35) gives the optimal reset wage as in Section 3.2

$$
w_{j, t}^{*}=\mu_{w} \frac{E_{t} \sum_{i=0}^{\infty}(\alpha \beta)^{i} n_{j, t+i}^{1+\eta}}{E_{t} \sum_{i=0}^{\infty}(\alpha \beta)^{i} \frac{n_{j, t+i}}{(1+\pi)^{i}}-E_{t} \sum_{i=0}^{\infty}(\alpha \beta)^{i} \psi_{j, t+i} \mathcal{I}_{j, t+i} \frac{n_{j, t+i}(1+\pi)^{i}}{}} .
$$

where $\mu_{w}=\frac{\theta \zeta}{\theta-1}$ denotes the markup. This is equation (8) in Section 3. Rearranging equation (40) yields the labor supply equation (9)

$$
\mu_{w}^{-1}=\frac{E_{t} \sum_{i=0}^{\infty}(\alpha \beta)^{i} n_{j, t+i}^{1+\eta}}{E_{t} \sum_{i=0}^{\infty}(\alpha \beta)^{i} \frac{w_{j, t}^{*} n_{j, t+i}}{(1+\pi)^{i}}-E_{t} \sum_{i=0}^{\infty}(\alpha \beta)^{i} \psi_{j, t+i} \mathcal{I}_{j, t+i} \frac{w_{j, t}^{*} n_{j, t+i}}{(1+\pi)^{i}}} .
$$

Note that envy and guilt needs to be considered separately, i.e. the term to the right in the denominator is defined as

$$
\begin{aligned}
& E_{t} \sum_{i=0}^{\infty}(\alpha \beta)^{i} \psi_{j, t+i} \mathcal{I}_{j, t+i} \frac{w_{j, t}^{*} n_{j, t+i}}{(1+\pi)^{i}}= \\
& \varepsilon E_{t} \sum_{i=0}^{\tau-1}(\alpha \beta)^{i} \mathcal{I}_{j, t+i} \frac{w_{j, t}^{*} n_{j, t+i}}{(1+\pi)^{i}}+\gamma E_{t} \sum_{i=\tau}^{\infty}(\alpha \beta)^{i} \mathcal{I}_{j, t+i} \frac{w_{j, t}^{*} n_{j, t+i}}{(1+\pi)^{i}}
\end{aligned}
$$

where $\tau$ denotes the threshold at which the worker exceeds the average income in the economy and $\psi_{j, t}$ is an indicator function, which takes values

$$
\psi_{j, t}=\left\{\begin{array}{lll}
\varepsilon & \text { for } & \mathcal{I}_{j, t}<0 \\
\gamma & \text { for } & \mathcal{I}_{j, t}>0
\end{array} .\right.
$$

Applying the downward sloping labor demand equation (31), we can write equation (41) in terms of aggregate labor.

$$
\mu_{w}^{-1}=\frac{E_{t} \sum_{i=0}^{\infty}\left(\alpha \beta(1+\pi)^{\theta(1+\eta)}\right)^{i} w_{j, t}^{-\theta(1+\eta)} y_{t+i}^{1+\eta}}{E_{t} \sum_{i=0}^{\infty}\left(\alpha \beta(1+\pi)^{(\theta-1)}\right)^{i} \frac{y_{t+i}}{w_{j, t}^{\theta-1}}-E_{t} \sum_{i=0}^{\infty}\left(\alpha \beta(1+\pi)^{(\theta-1)}\right)^{i} \psi_{j, t+i} \mathcal{I}_{j, t+i} \frac{y_{t+i}}{w_{j, t}^{\theta-1}}} .
$$


Rearranging terms

$$
\frac{w_{j, t}^{1+\theta \eta}}{\mu_{w}}=\frac{E_{t} \sum_{i=0}^{\infty}\left(\alpha \beta(1+\pi)^{\theta(1+\eta)}\right)^{i} y_{t+i}^{1+\eta}}{E_{t} \sum_{i=0}^{\infty}\left(\alpha \beta(1+\pi)^{(\theta-1)}\right)^{i} y_{t+i}-E_{t} \sum_{i=0}^{\infty}\left(\alpha \beta(1+\pi)^{(\theta-1)}\right)^{i} y_{t+i} \psi_{j, t+i} \mathcal{I}_{j, t+i}} .
$$

In the steady state we drop time indices

$$
\frac{w_{j}^{1+\theta \eta}}{\mu_{w}}=y^{\eta} \frac{E \sum_{i=0}^{\infty}\left(\alpha \beta(1+\pi)^{\theta(1+\eta)}\right)^{i}}{E \sum_{i=0}^{\infty}\left(\alpha \beta(1+\pi)^{(\theta-1)}\right)^{i}-\underbrace{E \sum_{i=0}^{\infty}\left(\alpha \beta(1+\pi)^{(\theta-1)}\right)^{i} \psi_{j, i} \mathcal{I}_{j, i}}_{\mathcal{E} \mathcal{G}}},
$$

In order to be able to solve the model numerically, we need to let the infinite sums converge. The sum formulation in the numerator can be written in terms of infinite geometric sums according to $\sum_{k=o}^{\infty} x^{k}=\frac{1}{1-x}$. In the case of the denominator this is a lot more complicated. Remember that there is a kink due to envy and guilt, which we need to account for. Therefore, let us look at the envy and guilt part separately for a moment, which is given by

$$
\mathcal{E} \mathcal{G}=E \sum_{i=0}^{\infty}\left(\alpha \beta(1+\pi)^{(\theta-1)}\right)^{i} \psi_{j, i} \mathcal{I}_{j, i}
$$

and needs to be split into two different intervals; envy and guilt

$$
=E \sum_{i=0}^{\tau-1}\left(\alpha \beta(1+\pi)^{(\theta-1)}\right)^{i} \psi_{j, i} \mathcal{I}_{j, i}+E \sum_{i=\tau}^{\infty}\left(\alpha \beta(1+\pi)^{(\theta-1)}\right)^{i} \psi_{j, i} \mathcal{I}_{j, i} .
$$

Furthermore, it holds in the steady state that $I_{j, i}=y\left[\left(\frac{w_{j}}{(1+\pi)^{i}}\right)^{1-\theta}-1\right]$ and that $\psi_{j, i}=\left\{\begin{array}{ll}\varepsilon & \text { for } \quad i<\tau-1 \\ \gamma & \text { for } i \geqslant \tau\end{array}\right.$ such that

$$
\begin{aligned}
= & \varepsilon y E \sum_{i=0}^{\tau-1}\left(\alpha \beta(1+\pi)^{(\theta-1)}\right)^{i}\left[\left(\frac{w_{j}}{(1+\pi)^{i}}\right)^{1-\theta}-1\right] \\
& +\gamma y E \sum_{i=\tau}^{\infty}\left(\alpha \beta(1+\pi)^{(\theta-1)}\right)^{i}\left[\left(\frac{w_{j}}{(1+\pi)^{i}}\right)^{1-\theta}-1\right] .
\end{aligned}
$$

which can be rewritten as

$$
\begin{aligned}
= & \varepsilon y w_{j}^{1-\theta} E \sum_{i=0}^{\tau-1}\left(\alpha \beta(1+\pi)^{2(\theta-1)}\right)^{i}-\varepsilon y E \sum_{i=0}^{\tau-1}\left(\alpha \beta(1+\pi)^{(\theta-1)}\right)^{i} \\
& +\gamma y w_{j}^{1-\theta} E \sum_{i=\tau}^{\infty}\left(\alpha \beta(1+\pi)^{2(\theta-1)}\right)^{i}-\gamma y E \sum_{i=\tau}^{\infty}\left(\alpha \beta(1+\pi)^{(\theta-1)}\right)^{i} .
\end{aligned}
$$


The sum formulation can be written in terms of (in-)finite geometric sums according to the following rules $\sum_{k=\tau}^{\infty} x^{k}=\frac{x^{\tau}}{1-x}$ and $\sum_{k=0}^{\tau-1} x^{k}=\frac{1-x^{(\tau-1)+1}}{1-x}$.

$$
\begin{gathered}
=\quad \varepsilon y w_{j}^{1-\theta} \frac{1-\left(\alpha \beta(1+\pi)^{2(\theta-1)}\right)^{\tau}}{1-\alpha \beta(1+\pi)^{2(\theta-1)}}-\varepsilon y \frac{1-\left(\alpha \beta(1+\pi)^{(\theta-1)}\right)^{\tau}}{1-\alpha \beta(1+\pi)^{(\theta-1)}} \\
+\gamma y w_{j}^{1-\theta} \frac{\left(\alpha \beta(1+\pi)^{2(\theta-1)}\right)^{\tau}}{1-\alpha \beta(1+\pi)^{2(\theta-1)}}-\gamma y \frac{\left(\alpha \beta(1+\pi)^{(\theta-1)}\right)^{\tau}}{1-\alpha \beta(1+\pi)^{(\theta-1)}}
\end{gathered}
$$

Plugging equation (51) back into equation (46) and applying the convergence rules to the numerator and the consumption part in the denominator yields

$$
\frac{w_{j}^{1+\theta \eta}}{\mu_{w}}=y^{\eta}\left(1-\alpha \beta(1+\pi)^{\theta(1+\eta)}\right)^{-1} *
$$

$$
\frac{1}{\frac{1}{1-\alpha \beta(1+\pi)^{\theta-1}}-\varepsilon y w_{j}^{1-\theta} \frac{1-\left(\alpha \beta(1+\pi)^{2(\theta-1)}\right)^{\tau}}{1-\alpha \beta(1+\pi)^{2(\theta-1)}}+\varepsilon y \frac{1-\left(\alpha \beta(1+\pi)^{\theta-1}\right)^{\tau}}{1-\alpha \beta(1+\pi)^{\theta-1}}-\gamma y w_{j}^{1-\theta} \frac{\left(\alpha \beta(1+\pi)^{2(\theta-1)}\right)^{\tau}}{1-\alpha \beta(1+\pi)^{2(\theta-1)}}+\gamma y{\frac{\left(\alpha \beta(1+\pi)^{\theta-1}\right)^{\tau}}{1-\alpha \beta(1+\pi)^{\theta-1}}} .}
$$

Note that for zero steady state inflation the envy and guilt parts cancel each other out and vanish.

$$
\begin{gathered}
\mu_{w}^{-1}=y^{\eta}(1-\alpha \beta)^{-1} \\
\frac{1}{\frac{1}{1-\alpha \beta}-\varepsilon y \frac{1-(\alpha \beta)^{\tau}}{1-\alpha \beta}+\varepsilon y N \frac{1-(\alpha \beta)^{\tau}}{1-\alpha \beta}-\gamma y \frac{(\alpha \beta)^{\tau}}{1-\alpha \beta}+\gamma y \frac{(\alpha \beta)^{\tau}}{1-\alpha \beta}}
\end{gathered}
$$

What remains is the standard formulation from a model without envy and guilt, i.e. $\mu_{w}^{-1}=y^{\eta}$.

\section{Linear Inequity Aversion}

In this section we give proof of the inviability of the original version of Fehr and Schmidt's (1999) utility function in our model setup. We show that for zero inflation, the model does not break down to the standard NKM with trend inflation.

Assume a utility function analogous to equation (3), only with inequity aversion entering linearly as suggested by Fehr and Schmidt (1999).

$$
U(c, l, I)=c_{j, t}-\zeta \frac{n_{j, t}^{1+\eta}}{1+\eta}-\psi_{j, t} I_{j, t}
$$

Income inequality $I_{j, t}$ is again defined by equation (4). Under linear inequity aversion $I_{j, t}$ changes signs, depending on the position in the income distribution, i.e. $I_{j, t}<0$ for having a lower than average real income and $I_{j, t}>0$ for having a higher than average real income. To make sure that inequity aversion always 
enters utility negatively, we calibrate the envy and guilt parameters according to the following scheme:

$$
\psi_{j, t}=\left\{\begin{array}{lll}
-\varepsilon & \text { for } & \mathcal{I}_{j, t}<0 \\
\gamma & \text { for } & \mathcal{I}_{j, t}>0
\end{array} .\right.
$$

Everything else equal, a resetting worker chooses the optimal reset wage to be

$$
w_{j, t}^{*}=\mu_{w} \frac{E_{t} \sum_{i=0}^{\infty}(\alpha \beta)^{i} n_{j, t+i}^{1+\eta}}{E_{t} \sum_{i=0}^{\infty}(\alpha \beta)^{i} \frac{n_{j, t+i}}{(1+\pi)^{i}}-E_{t} \sum_{i=0}^{\infty}(\alpha \beta)^{i} \psi_{j, t+i} \frac{n_{j, t+i}(1+\pi)^{i}}{}} .
$$

which according to the above derivation has a steady state equivalent in aggregate terms of

$$
\frac{w_{j}^{1+\theta \eta}}{\mu_{w}}=y^{\eta} \frac{E \sum_{i=0}^{\infty}\left(\alpha \beta(1+\pi)^{\theta(1+\eta)}\right)^{i}}{E \sum_{i=0}^{\infty}\left(\alpha \beta(1+\pi)^{(\theta-1)}\right)^{i}-\underbrace{E \sum_{i=0}^{\infty}\left(\alpha \beta(1+\pi)^{(\theta-1)}\right)^{i} \psi_{j, i}}_{\mathcal{E} \mathcal{G}}} .
$$

Again, looking at envy and guilt (the right term in the denominator) more closely yields

$$
\mathcal{E} \mathcal{G}=-\varepsilon E \sum_{i=0}^{\tau-1}\left(\alpha \beta(1+\pi)^{(\theta-1)}\right)^{i}+\gamma E \sum_{i=\tau}^{\infty}\left(\alpha \beta(1+\pi)^{(\theta-1)}\right)^{i} .
$$

Letting the (in)finite sums converge yields

$$
\mathcal{E} \mathcal{G}=-\varepsilon \frac{1-\left(\alpha \beta(1+\pi)^{(\theta-1)}\right)^{\tau}}{1-\alpha \beta(1+\pi)^{(\theta-1)}}+\gamma \frac{\left(\alpha \beta(1+\pi)^{(\theta-1)}\right)^{\tau}}{1-\alpha \beta(1+\pi)^{(\theta-1)}} .
$$

Consequently, equation (57) can be written as

$$
\frac{w_{j}^{1+\theta \eta}}{\mu_{w}}=y^{\eta} \frac{\left(1-\alpha \beta(1+\pi)^{\theta(1+\eta)}\right)^{-1}}{\left(1-\alpha \beta(1+\pi)^{(\theta-1)}\right)^{-1}+\varepsilon \frac{1-\left(\alpha \beta(1+\pi)^{(\theta-1)}\right)^{\tau}}{1-\alpha \beta(1+\pi)^{(\theta-1)}}-\gamma \frac{\left(\alpha \beta(1+\pi)^{(\theta-1)}\right)^{\tau}}{1-\alpha \beta(1+\pi)^{(\theta-1)}}} .
$$

Note that this equation breaks down to the standard version only if we assume envy and guilt to be absent, i.e. $\varepsilon=\gamma=0$. In case of zero inflation there is no envy and guilt due to the fact that there is no wage dispersion.

$$
\mu_{w}^{-1}=y^{\eta} \frac{(1-\alpha \beta)^{-1}}{(1-\alpha \beta)^{-1}+\varepsilon \frac{1-(\alpha \beta)^{\tau}}{1-\alpha \beta}-\gamma \frac{(\alpha \beta)^{\tau}}{1-\alpha \beta}} .
$$

However, equation (60) still inhabits the second component in the denominator, governing the disutility from inequity aversion. Therefore, envy and guilt influence the steady state even when there is no envy and guilt in action. From this we conclude that the linear version of the Fehr and Schmidt (1999) utility function is not viable in our standard DSGE model. 


\section{The Welfare Function}

Usually, one needs to take the per-period utility and plug in the expressions $c_{j}=y(\pi)$ and $n_{j}=s y(\pi)$, with $s$ being the price dispersion and $y(\pi)$ being the optimal output which I have derived from my optimization problem, i.e. the Phillips curve. Hence, the optimal inflation rate is the value $\pi$ which gives me the max utility. This approach cannot be implemented in the model with envy and guilt as well. The problem that arises with this procedure in the envy model is, however, that the per period utility function is not stable across time. In the envy and guilt model it is

$$
U=\frac{c_{j, t}^{1-\sigma}}{1-\sigma}-\zeta \frac{n_{j, t}^{1+\eta}}{1+\eta}-\psi_{j, t} \frac{\mathcal{I}_{j, t}^{2}}{2}
$$

where the latter term is time dependent. If you reset your wage, you feel envy. On the other hand, if you haven't reset your wage for a while, you feel guilt. So there is a discontinuity in the utility function with respect to time, which causes $\psi_{j, t}$ to take two different values. I can overcome this problem by putting the steady state Phillips curve into the converging utility function.

$$
\begin{aligned}
U & =\sum_{i=0}^{\infty}(\alpha \beta)^{i}\left[\frac{c_{j, t+i}^{1-\sigma}}{1-\sigma}-\zeta \frac{n_{j, t+i}^{1+\eta}}{1+\eta}-\psi_{j, t+i} \frac{\mathcal{I}_{j, t+i}^{2}}{2}\right] \\
& \left.=\sum_{i=0}^{\infty}(\alpha \beta)^{i} \frac{c_{j, t+i}^{1-\sigma}}{1-\sigma}-\sum_{i=0}^{\infty} \zeta(\alpha \beta)^{i} \frac{n_{j, t+i}^{1+\eta}}{1+\eta}-\varepsilon \sum_{i=0}^{\tau-1}(\alpha \beta)^{i} \frac{\mathcal{I}_{j, t+i}^{2}}{2}-\gamma \sum_{i=\tau}^{\infty}(\alpha \beta)^{i} \frac{\mathcal{I}_{j}^{2}}{2}{ }^{2} \sigma_{+j}\right) \\
& =\sum_{i=0}^{\infty}(\alpha \beta)^{i} \frac{c_{j, t+i}^{1-\sigma}}{1-\sigma}-\sum_{i=0}^{\infty} \zeta(\alpha \beta)^{i} \frac{\left(\left(\frac{w_{j, t}}{(1+\pi)^{i}}\right)^{-\theta} y_{t+i}\right)^{1+\eta}}{1+\eta} \\
-\varepsilon \sum_{i=0}^{\tau-1}(\alpha \beta)^{i} & \frac{\mathcal{I}_{j, t+i}^{2}}{2}-\gamma \sum_{i=\tau}^{\infty}(\alpha \beta)^{i} \frac{\mathcal{I}_{j, t+i}^{2}}{2}
\end{aligned}
$$

applying the definition of inequity $\mathcal{I}$, dropping time indices and re-writing the finite and infinite sums in terms of fintite and infinite geometric sums, we find

$$
\begin{aligned}
U= & \frac{\frac{y(\pi)^{1-\sigma}}{1-\sigma}}{1-\alpha \beta}-\frac{\zeta w_{j}^{-\theta(1+\eta)} \frac{y(\pi)^{1+\eta}}{1+\eta}}{1-\alpha \beta \pi^{\theta(1+\eta)}} \\
& -\frac{\varepsilon}{2} y(\pi)^{2} \underbrace{\left[w_{j}^{2(1-\theta)} \frac{1-\left(\alpha \beta(1+\pi)^{2(\theta-1)}\right)^{\tau}}{1-\alpha \beta(1+\pi)^{2(\theta-1)}}-2 w_{j}^{1-\theta} \frac{1-\left(\alpha \beta(1+\pi)^{\theta-1}\right)^{\tau}}{1-\alpha \beta(1+\pi)^{\theta-1}}+\frac{1-(\alpha \beta)^{\tau}}{1-\alpha \beta}\right]}_{a(\pi)} \\
& -\frac{\gamma}{2} y(\pi)^{2} \underbrace{\left[w_{j}^{2(1-\theta)} \frac{\left(\alpha \beta(1+\pi)^{2(\theta-1)}\right)^{\tau}}{1-\alpha \beta(1+\pi)^{2(\theta-1)}}-2 w_{j}^{1-\theta} \frac{\left(\alpha \beta(1+\pi)^{\theta-1}\right)^{\tau}}{1-\alpha \beta(1+\pi)^{\theta-1}}+\frac{(\alpha \beta)^{\tau}}{1-\alpha \beta}\right]}_{b(\pi)}
\end{aligned}
$$


or in short

$$
U=\frac{\frac{y(\pi)^{1-\sigma}}{1-\sigma}}{1-\alpha \beta}-\frac{\zeta w_{j}^{-\theta(1+\eta)} \frac{y(\pi)^{1+\eta}}{1+\eta}}{1-\alpha \beta \pi^{\theta(1+\eta)}}-\frac{y(\pi)^{2}}{2}[\varepsilon a(\pi)+\gamma b(\pi)]
$$

Now we can again plug in $y(\pi)$ and find the maximizing inflation rate.

\subsection{The labor supply elasticity}

The labor supply elasticity is the labor supply elasticity, holding the marginal utility of wealth constant. It is the elasticity most papers and the empirical findings refer to. In the zero inflation steady state (where there is no envy and guilt and hence, we can omit the income inequality term from our utility function) it is defined as

$$
\varepsilon=\frac{\partial n}{\partial w} \frac{w}{n}
$$

where $\lambda$ is the langrangian multiplier. To derive $\varepsilon$ in a general form, I assume the utility function

$$
\max \sum_{t=0}^{\infty} \beta^{t} U\left(c_{t}, n_{t}\right)
$$

subject to

$$
c_{t}+m_{t+1}+b_{t+1}=w_{t} n_{t}+r_{t} b_{t}+m_{t}
$$

with the FOC's

$$
\begin{aligned}
& \frac{\partial L}{\partial c}=U_{c_{t}}-\lambda_{t}=0 \\
& \frac{\partial L}{\partial n}=-U_{n_{t}}+\lambda_{t} w_{t}=0
\end{aligned}
$$

which is

$$
\begin{aligned}
U_{c_{t}} & =\lambda_{t} \\
-U_{n_{t}} & =\lambda_{t} w_{t}
\end{aligned}
$$

or put differently (since $c$ and $n$ are functions of $\lambda$ and $w$ )

$$
\begin{aligned}
& \frac{\partial U(c(\lambda, w), n(\lambda, w))}{\partial c}=\lambda \\
& \frac{\partial U(c(\lambda, w), n(\lambda, w))}{\partial n}=-\lambda w
\end{aligned}
$$

taking the partial derivatives with respect to $w$

$$
\begin{aligned}
U_{c c} \frac{\partial c}{\partial w}+U_{c n} \frac{\partial n}{\partial w} & =0 \\
U_{n c} \frac{\partial c}{\partial w}+U_{n n} \frac{\partial n}{\partial w} & =-\lambda
\end{aligned}
$$


solving both sides for $\frac{\partial c}{\partial w}$

$$
\begin{aligned}
-\frac{\partial c}{\partial w} & =\frac{U_{c n}}{U_{c c}} \frac{\partial n}{\partial w} \\
-\frac{\partial c}{\partial w} & =\left(\lambda+U_{n n} \frac{\partial n}{\partial w}\right) \frac{1}{U_{n c}}
\end{aligned}
$$

and setting them equal

$$
\frac{U_{c n}}{U_{c c}} \frac{\partial n}{\partial w}=\left(\lambda+U_{n n} \frac{\partial n}{\partial w}\right) \frac{1}{U_{n c}}
$$

we can solve this for $\frac{\partial n}{\partial w}$

$$
\frac{\partial n}{\partial w}=\frac{\lambda}{\frac{U_{n c} U_{c n}}{U_{c c}}-U_{n n}}
$$

replacing $\lambda$

$$
\frac{\partial n}{\partial w}=\frac{-\frac{U_{n}}{w}}{\frac{U_{n c} U_{c n}}{U_{c c}}-U_{n n}}
$$

multiplying both sides with $\frac{w}{n}$

$$
\frac{\partial n}{\partial w} \frac{w}{n}=\frac{U_{n}}{n\left[U_{n n}-\frac{U_{n c} U_{c n}}{U_{c c}}\right]}
$$

meaning

$$
\varepsilon=\frac{U_{n}}{n\left[U_{n n}-\frac{U_{n c} U_{c n}}{U_{c c}}\right]}
$$

given our utility function

$$
U\left(c_{t}, n_{t}\right)=c_{t}-\zeta \frac{n_{t}^{1+\eta}}{1+\eta}
$$

we have:

$$
\begin{aligned}
U_{c} & =1 \\
U_{c c} & =0 \\
U_{c n} & =0 \\
U_{n} & =\zeta n_{t}^{\eta} \\
U_{n n} & =\zeta \eta n_{t}^{\eta-1} \\
U_{n c} & =0
\end{aligned}
$$


such that

$$
\begin{aligned}
\varepsilon & =\frac{\zeta n_{t}^{\eta}}{n\left[\zeta \eta n_{t}^{\eta-1}-0\right]} \\
\varepsilon & =\frac{\zeta n_{t}^{\eta}}{\zeta \eta n_{t}^{\eta-1} n} \\
\varepsilon & =\frac{\zeta n_{t}^{\eta}}{\zeta \eta n_{t}^{\eta}} \\
\varepsilon & =\frac{1}{\eta}
\end{aligned}
$$

\subsection{Figures}
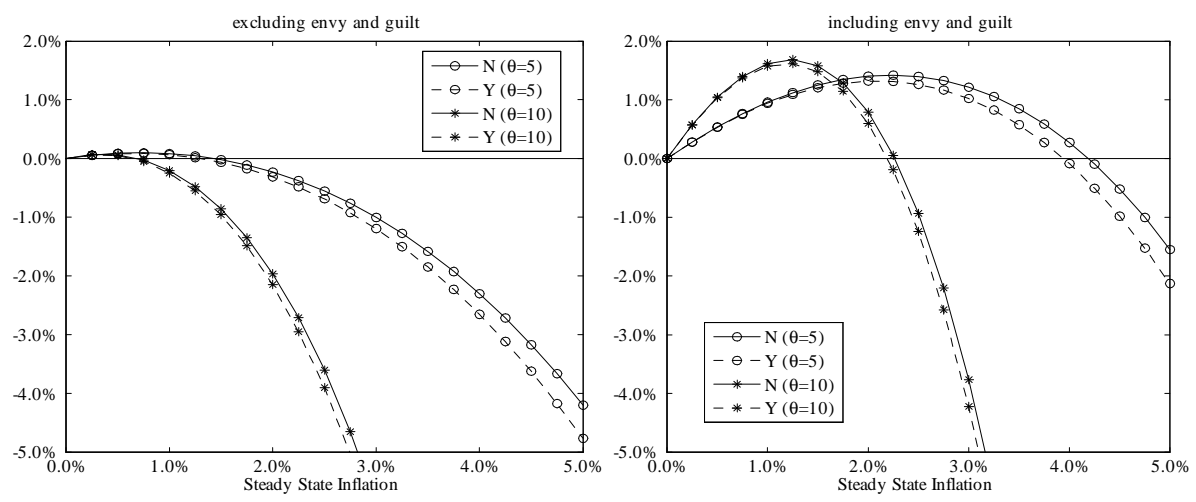

Figure 6: Sensitivity with respect to substitution elasticity 